\title{
On the Structure of Intermediate-Scale Disturbances on the Baiu Front
}

\author{
By Sadao Yoshizumi \\ Meteorological Research Institute, Tokyo \\ (Manuscript received 2 July 1976, in revised form 15 December 1976)
}

\begin{abstract}
The present study will treat two intermediate-scale disturbances developing on the Baiu front with a wavelength of about $2,500 \mathrm{~km}$ and of about $1,000 \mathrm{~km}$. Three-dimensional structure of the longer wave is analyzed with the aid of the vertical-longitudinal cross sections by means of the harmonic analysis of 6-hourly data, and the shorter wave by means of composite technique.

The results show that these disturbances with a shallow vertical extension below the $400-\mathrm{mb}$ level are of warm-core type and the vertical structures are different between north of and in the mean Baiu frontal zone. North of the front, it is cold in the trough, which has a slightly forward tilt. In the frontal zone it is warm in the trough, the axis of which tilts backward vertically. On the horizontal map, the trough line runs NW-to-SE in the northern part and SW-to-NE in the southern part. Velocity divergence and vertical component of relative vorticity have a magnitude of the same order.

The disturbance developed in a narrow zone of strong gradient of a Richardson number in the one-week mean field. As it develops, a warm core in the upper layer of the low becomes intense through the latent heat release.
\end{abstract}

\section{Introduction}

Smaller-scale disturbances such as small depressions and fronts, which are called as intermediate- or medium-scale ones (Eliassen, 1966; Sawyer, 1967), have gained more attention because their physical mechanism has not been fully understood and their physical processes have not been handled in numerical weather prediction models despite their important role in the weather phenomena. In addition, numerical experiments with the general circulation model by Manabe et al. (1970) indicate that the consideration of these disturbances leads to better understanding of the atmospheric general circulation.

Recently great progress has been made in theoretical studies on atmospheric dynamics of intermediate scale. From re-examination of a classical problem of frontal instability, Orlanski (1968) and Kasahara and Rao (1972) found that there exist unstable waves at all wavelength, including intermediate-scale region which has been considered to be stable.

Extended theoretical studies by Stone (1966),
Gambo (1970a) and Tokioka (1970) revealed the general character of baroclinic instability. As a Richardson number becomes smaller, a geostrophic baroclinic wave has a maximum growth rate at a larger longitudinal wavenumber. In a Richardson number of order of unity, a maximum growth rate occurs in an intermediate scale. Tokioka (1971) suggested the possibility that the geostrophic baroclinic wave in a small Richardson number gives an explanation of intermediatescale disturbances on the Baiu front, and he showed that intermediate-scale disturbances have a preferred scale at a finite lateral wavenumber with incorporation of convective effects under a conditionally unstable stratification (Tokioka, 1973). Also, Gambo (1970b), Tokioka (1972) and Nitta and Ogura (1972) investigated intermediate-scale disturbances numerically simulated.

Compared with the above theoretical studies, however, there are not many analytical studies about detailed structure of intermediate-scale disturbances in the real atmosphere, though intermediate-scale cyclones generate nearly with the same frequency as that of synoptic-scale ones 
(Nitta and Yamamoto, 1973). Matsumoto, Yoshizumi and Takeuchi (1970) (hereafter referred to as MYT) pointed out that gradually developing disturbances with $1,000 \mathrm{~km}$ scale on the Baiu front have a characteristic thermal structure different from that of an ordinary baroclinic wave. In the lower layers the air is cold in the low pressure region and warm in the high pressure region, and the horizontal temperature distribution becomes reversed in the upper layers. Similar structure was reported by Ninomiya and Akiyama (1971) who analyzed the development process of a disturbance with a horizontal scale of several hundred kilometers on the Baiu front.

To the contrary, Nitta, Nanbu and Yoshizaki (1973) analyzed disturbances with a wavelength of about $2,000 \mathrm{~km}$ which occurred near the Southwest Islands, Japan at the southern margin of the Siberian airmass in winter and they found that disturbances have vertical structure similar to that of an ordinary baroclinic wave. Therefore, there seems to be other types of intermediate-scale disturbance. From their investigation based on weather maps routinely drawn, Nitta and Yamamoto (1974) proposed the classification of intermediate-scale disturbances into four types. However, they did not give a physical interpretation to four types of structure.

These previous analytical studies are based exclusively on a longitudinal cross section. Although Nitta and Yamamoto (1974) examined the transverse cross sections, they did not reveal the detailed transverse structure. In the light of the theoretical studies, it is necessary to examine its transverse structure in order to construct more consistent picture of the disturbance on intermediate scale. For this purpose, two kinds of disturbance will be examined in the present paper; one is the disturbance with a period of two days, and the other with a period of one day. The former is analyzed by the harmonic analysis of time-series data at various stations to reveal its transverse as well as longitudinal structure. The latter, which has been treated by MYT, is reexamined by means of the composite technique.

\section{Disturbances with a period of two days}

In this section an analysis will be made of the structure of disturbances with a period of about two days on the Baiu front in June, 1969. For the occasion 6-hourly rawinsonde observations were made at aerological stations of the Japan

\footnotetext{
* As to location of stations, see Fig. 13.
}

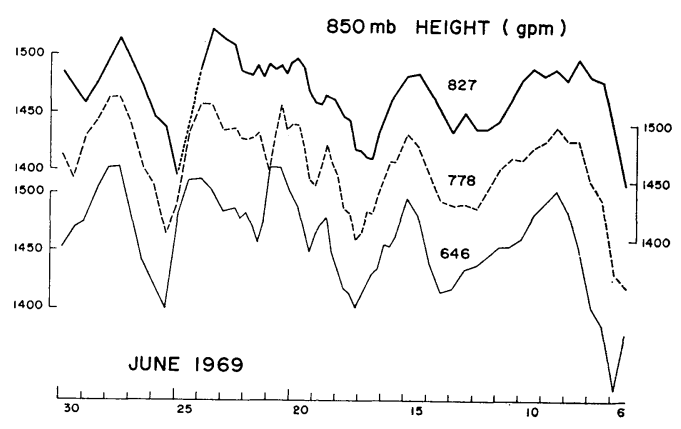

Fig. 1 Changes of observed height of the 850mb surface at Kagoshima (47 827), Shionomisaki (47 778) and Tateno (47 646) from June 6 to 30, 1969.

Meteorological Agency during the period from 09 JST, June 16 to 09 JST, June 23, 1969. These aerological data were used to analyze detailed three-dimensional structure of the disturbance. Fig. 1 shows the time change of the $850 \mathrm{mb}$ height observed at Kagoshima, Shionomisaki and Tateno*) from June 6 to 30, 1969. Obviously variations with a period of several days were predominant over the whole period here shown. Furthermore, superposed on this variation one with a shorter period of about two days appeared to propagate eastwards during the period from June 16 to 23 .

In order to see the period of predominant variations roughly, a sinusoidal curve,

$$
A \sin \left(\frac{2 \pi}{T} t+\alpha\right)+A_{0}
$$

with a given period, $T$, is fitted to $900-\mathrm{mb}$ heights observed at Shionomisaki from 09 JST, June 16 to 09 JST, June 23. An amplitude, $A$, a phase angle, $\alpha$, and a constant, $A_{o}$, are determined so as to minimize the root mean square of the differences between the observed values and calculated ones from the sinusoidal curve (1). In Fig. 2 resulted amplitude and the r.m.s. of the differences are drawn as a function of the period, $T$. This figure reveals three definite peaks of the amplitude and corresponding minima of the r.m.s. of the residual at periods of several days, 2 days and one day. A peak at a period of several days is due to a long wave, as was also seen in Fig. 1, and one at a period of one day due to the solar diurnal variation. The period of the variation to be analyzed below is estimated to be 51 hours $(=2.1$ days) from Fig. 2. 


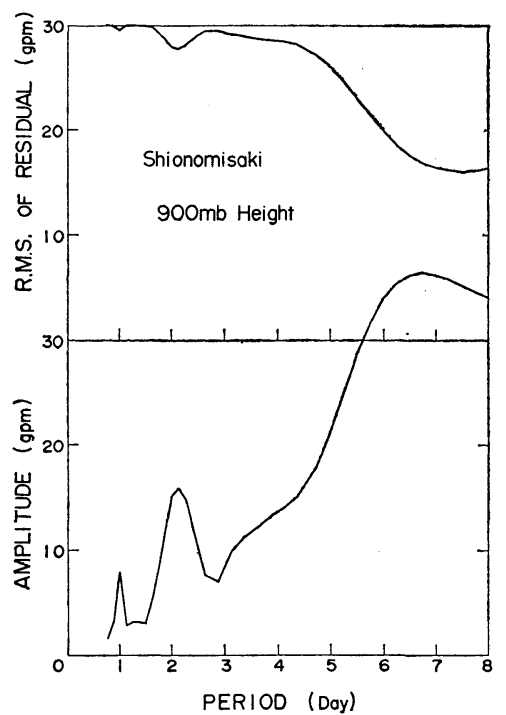

Fig. 2 Lower: Amplitude of the best-fitted sinusoidal curve to the $900-\mathrm{mb}$ height observed at Shionomisaki as a function of the period. Upper: The root-meansquare of the difference between the observed height and calculated one from the sinusoidal curve.

\subsection{Method of analysis}

Variation of any quantity with a period longer than several days was eliminated by computing an anomaly from a running mean of 9 values observed at 6-hour intervals. Fig. 3 is a verticaltime cross section of height and temperature anomalies at Shionomisaki, which were corrected for a diurnal variation in order to make more clear the variation with a period of two days. Correction was made with diurnal variations at Wajima which were determined from 6-hourly data for a total of 61 days obtained from 1965 to 1968 . Evidently Fig. 3 depicts some features of the disturbance with a period of two days. Thermal structure shows such characteristic feature that in the lower layer the temperature anomaly tends to be negative in the low pressure and positive in the high pressure, similar to that pointed out by MYT.

In the present study, in order to make more objective analysis of the structure, variation components with a period of two days were picked up by means of the harmonic analysis, which was applied to the anomalies over two periods from 15 JST on the 18th to 09 JST on the 22nd. The result of the harmonic analysis for Shionomisaki, which corresponds to Fig. 3, is illustrated
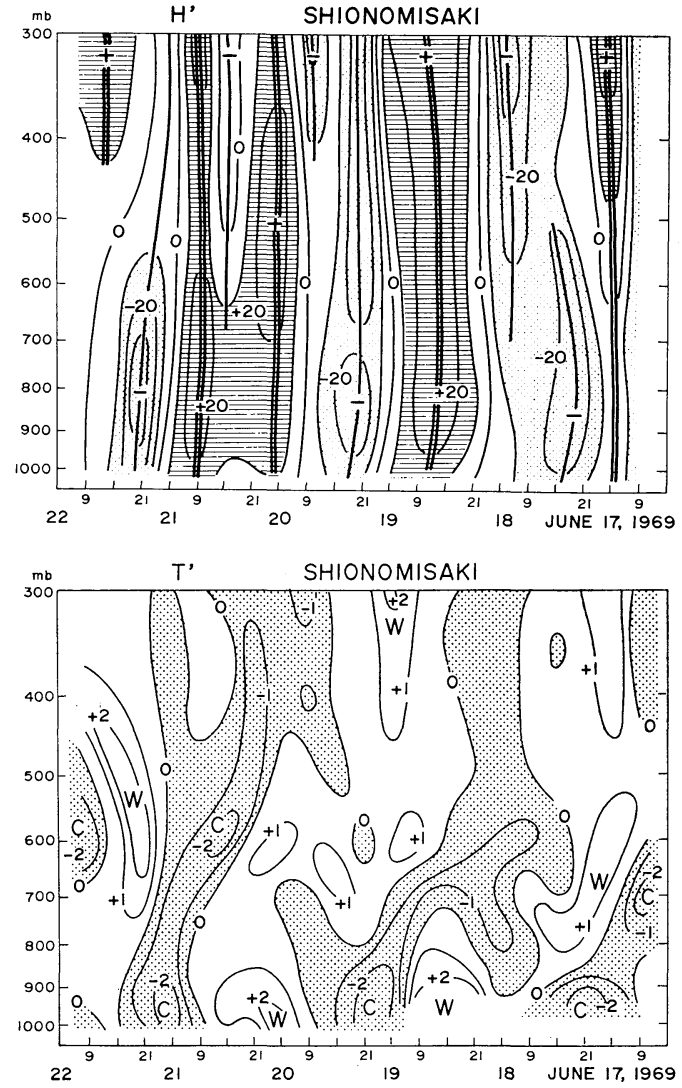

Fig. 3. Vertical-time cross sections of height and temperature anomalies at Shionomisaki, shown in the upper and the lower parts, respectively. Area of height anomaly larger than $+10 \mathrm{gpm}$ is horizontally hatched, and area of negative temperature anomaly is stippled.

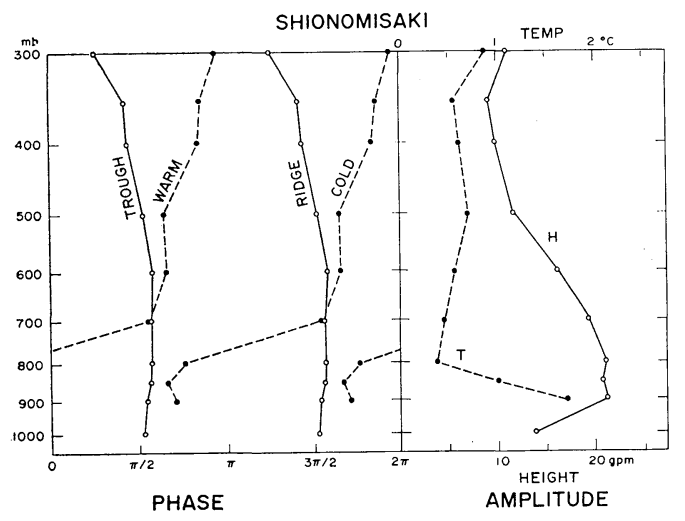

Fig. 4a Vertical profile of variation component with a period of two days at Shionomisaki. Solid line: height; dashed line: temperature. 
in Fig. 4a. In the left part of this figure the time runs from the right to the left and the phase angle $2 \pi$ corresponds to the time of 15 JST on the 18 th or 20 th. This figure can also be considered as a vertical-longitudinal cross section along a line passing over the station parallel to the movement direction of the disturbance. From comparison between Figs. 3 and $4 \mathrm{a}$ it is evident that the result of the harmonic analysis enables us to grasp essential features of the vertical structure objectively and easily, though its details are lost. In this section, therefore, threedimensional features of the disturbance will be deduced from the vertical-longitudinal cross sections at various stations by means of the harmonic analysis.

\subsection{Height and temperature fields}

Figs. 4a to $c$ illustrate the phase and amplitude of height and temperature variations at Shionomisaki, Tateno and Hachijojima, respectively, determined from the harmonic analysis. It is noted that the profiles at Shionomisaki and Tateno

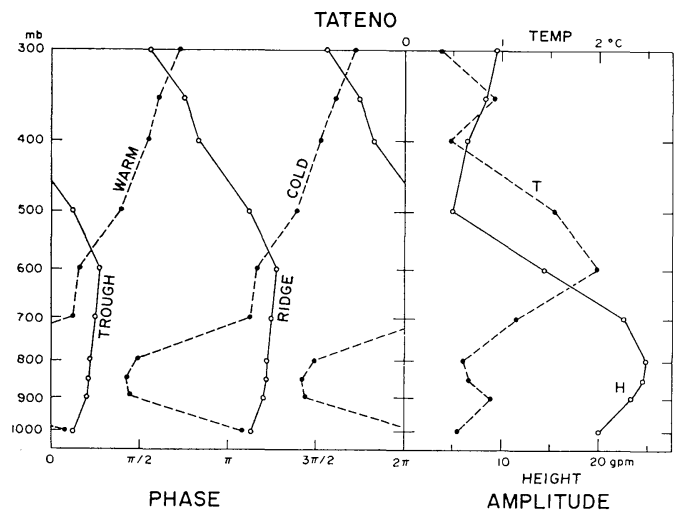

Fig. 4b The same as Fig. 4a, except at Tateno.

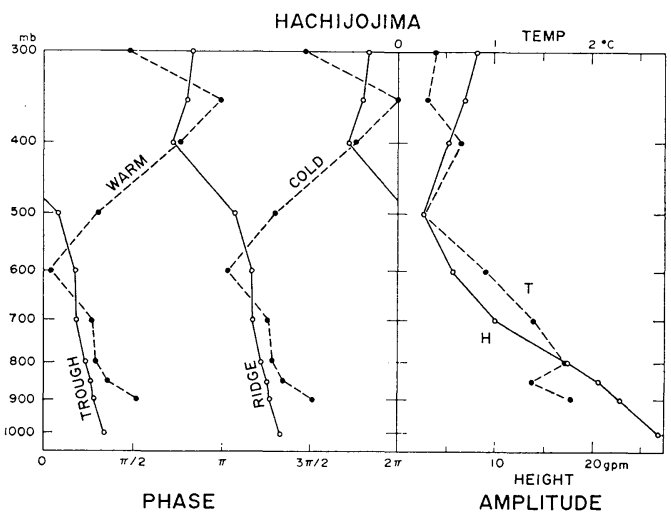

Fig. 4c The same as Fig. 4a, except at Hachijojima. are similar to each other, and that the profile at Hachijojima is different from two others. This fact suggests that there exists a marked difference in the vertical-longitudinal structure between in the northern and the southern parts of the disturbance.

During the period of this analysis Tateno and Shionomisaki were situated in the north side of the surface center of the disturbance, and the profiles there show that the air temperature is low in the trough and high in the ridge in the lower layer below the $800-\mathrm{mb}$ level. Above the $800-\mathrm{mb}$ level the reversed phase relationship between height and temperature variations was observed. This characteristic in thermal field is similar to those in the disturbance with the wavelength of about $1,000 \mathrm{~km}$ analyzed by MYT and in the disturbance with a horizontal scale of several hundred kilometers by Ninomiya and Akiyama (1971). The vertical axes of the trough and the ridge have slightly forward or eastward tilt below the $600-\mathrm{mb}$ level and backward or westward tilt above it.

On the other hand, at Hachijojima which was situated just on the south side of the center of the surface disturbance, the analysis (Fig. 4c) indicates that the disturbance has a verticallongitudinal structure different from that on the north side. It is cold in the ridge and warm in the trough throughout the lower troposphere. On the vertical-longitudinal cross section vertical axes of the trough and the ridge tilts backward or

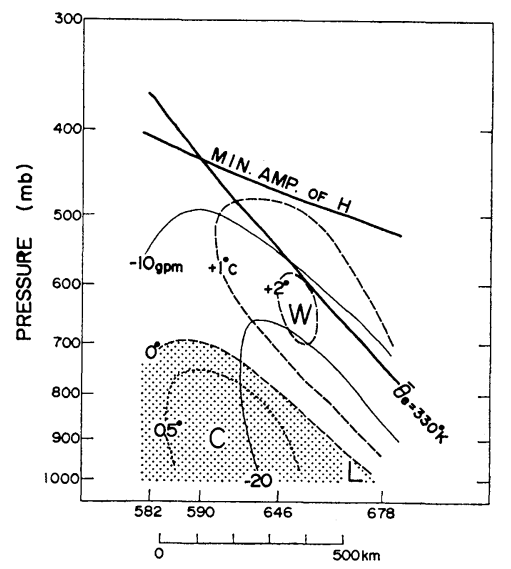

Fig. 5 Vertical-lateral cross section in the low pressure region. Height anomaly is denoted by thin solid lines labelled in gpm, and temperature anomaly by dashed lines labelled in ${ }^{\circ} \mathrm{C}$. Stippled area is a negative temperature anomaly one. 
westward, but the phase relation between height and temperature anomalies is not the same as that in an ordinary baroclinic wave, where it is warm in front of the trough and cold in the rear of it.

The above-mentioned north-south contrast in the vertical-longitudinal structure results from a structure with a northward tilt. Fig. 5 is a transverse cross section in the trough on the basis of the analyses at Hachijojima, Tateno, Sendai and Akita along the $140^{\circ} \mathrm{E}$ meridian, by taking account of the phase differences due to the eastward propagation of the disturbance. Cold region north of the disturbance is confined to below the $800-\mathrm{mb}$ level at Tateno, and the $700-\mathrm{mb}$ level at Akita and Sendai. Above the cold region warm air occupies with a warm core at $600 \mathrm{mb}$ over the low. As expected from the hydrostatic relation, a minimum of height anomaly in the vertical is observed at the level of zero temperature anomaly, and above it negative height anomaly decreases in magnitude toward a minimum in height amplitude within the range between $500 \mathrm{mb}$ over Hachijojima and $400 \mathrm{mb}$ over Akita, which may be considered to indicate the top of the disturbance.

In Fig. 5 a thick solid line represents a surface with a mean equivalent potential temperature $\left(\theta_{e}\right)$ of $330^{\circ} \mathrm{K}$ over the period from 15 JST on the 18th to 09 JST on the 22nd. From Saito's (1966) criterion for airmass identification, the surface $\theta_{e}=330^{\circ} \mathrm{K}$ may be considered as a mean position of the Baiu frontal zone over the period under consideration. Taking account of the mean temperature field (see Fig. 19), the transverse temperature distribution shown in Fig. 5 can be interpreted as follows; the Baiu front shifts northward with intense horizontal temperature gradient in the low pressure region, while in the high pressure region the front shifts southward with weak temperature gradient. Such situation is seen in Figs. 6a and $b$, which display the horizontal distributions of height and temperature anomaly at $900 \mathrm{mb}$ and $600 \mathrm{mb}$ based on the time-to-space conversion of the results of the harmonic analyses at Hachijojima, Tateno, Sendai and Akita. At the $900-\mathrm{mb}$ level regions of negative temperature anomaly are found in the northeast of the low and in the southeast of the high, and regions of positive anomaly in the southeast of the low and in the northeast of the high. Thus, strongest temperature gradient occurs in the front of the low. At the $600-\mathrm{mb}$ level pronounced warm and cold regions lie over the low and the high, respectively. Centers of the low and of the high

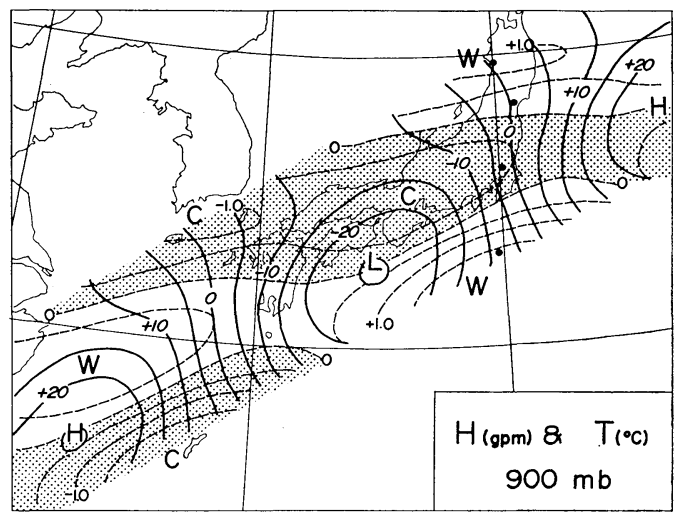

Fig. 6a Horizontal map at $900 \mathrm{mb}$ drawn by the time-to-space conversion based on analyzed time variations at Hachijojima, Tateno, Sendai and Akita. Height and temperature anomalies are indicated by solid and dashed lines, respectively. Area of negative temperature anomaly is stippled.

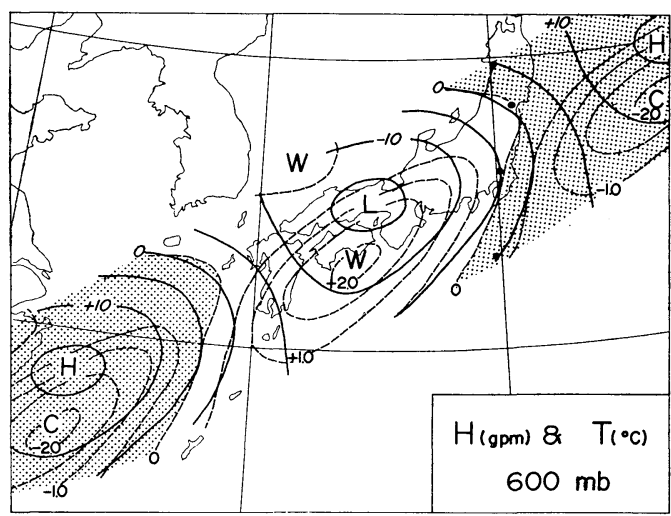

Fig. 6b The same as Fig. 6a, except at $600 \mathrm{mb}$.

shift northward and their intensity weakens, compared with those at $900 \mathrm{mb}$. This vertical change is consistent with temperature anomaly distributions.

\subsection{Wavelength and phase speed}

The wavelength and phase speed of the disturbance can be evaluated from the phase differences of height variation between various stations. In Fig. 7 the numerals below the dots, indicating the location of stations, are estimated phase differences of $900-\mathrm{mb}$ height variations from that at Shionomisaki, and its isopleths are denoted by dashed lines.

From Fig. 7 the wavelength of the disturbance is estimated to be $2,700 \mathrm{~km}$ and its phase speed $56 \mathrm{~km} / \mathrm{hr}(=16 \mathrm{~m} / \mathrm{sec})$. In general the upper 


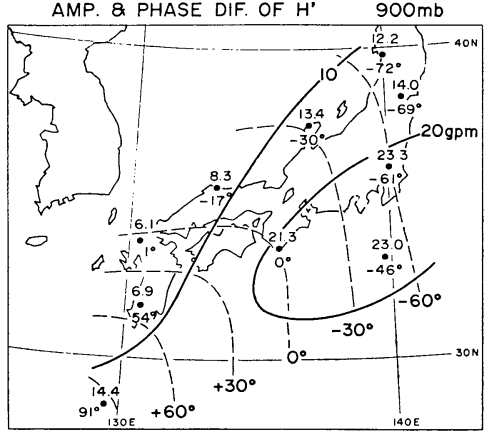

Fig. 7 Distribution of estimated amplitude and phase angle of $900-\mathrm{mb}$ height variation. Phase angle is relative value to that at Shionomisaki.

limit of intermediate scale is about $2,000 \mathrm{~km}$ (c.f., Yoshizumi, 1974). The disturbance under consideration has a longer wavelength than the ever defined upper limit. However, the disturbance may considered as an intermediate-scale one, judging from the fact that its structure is different from that of an ordinary baroclinic wave. Besides it is quite similar in the northern part to those of intermediate-scale disturbance on the Baiu front (MYT; Ninomiya and Akiyama, 1971). Therefore, the upper limit of intermediate-scale may be put on a larger scale, say, $3,000 \mathrm{~km}$, in the vicinity of Japan Islands.

In the normal direction to the movement of the disturbance, the phase in the northern part is ahead of that in the southern part since the disturbance travels eastnortheastwards. In other words, the trough and the ridge run SW-to-NE. This transverse change in phase is not in agreement with that of an intermediate-scale disturbance theoretically obtained under an influence of convective effects (Tokioka, 1973). In the northern part of the disturbance the trough line orients NW-to-SE, as clear over the western Japan in Fig. 7 and also at the $600-\mathrm{mb}$ level in Fig. 6 b.

\subsection{Development of the disturbance}

The disturbance developed slowly as it moved eastwards. Fig. 7 shows the distribution of estimated amplitude of the $900-\mathrm{mb}$ height variation of a two-day period by the upper numerals and solid lines in gpm. Estimated amplitude is about $14 \mathrm{gpm}$ at Naze and about $23 \mathrm{gpm}$ at Tateno where the phase is behind by about $150 \mathrm{deg}$. compared with that at Naze. Thus, amplitude of the 900-mb height increases about 1.4 times for about 20 hours; that is, the growth rate of the disturbance is estimated to be 60 hours (2.5 days) in e-folding time, provided that the disturbance grew exponentially.

It is interesting that the thermal structure of the disturbance changed with the development. In addition to the similar vertical profiles of phase in height and temperature anomalies at Shionomisaki and Tateno, a marked difference can be noted between profiles of temperature amplitudes at two stations. The estimated amplitude of temperature at Tateno is larger in the layer between 500 and $400 \mathrm{mb}$ and smaller near the 900-mb level than that at Shionomisaki. This may be resulted from the modification in thermal field accompanied by the development; the intensification of a warm core in the upper layer and the decrease of temperature fall in the lower layer in the low pressure region. Similar change in thermal field is reported by Ninomiya and Akiyama (1971). As they described, release of latent heat in the low pressure may have a main contribution to the intensification of a warm core in the upper layer. In fact, large mean precipitation as much as $20 \mathrm{~mm} /$ day was observed in the southern tip of the Boso Peninsula over the period under consideration. As a result of the intensification of the warm core, eastward and westward tilt of the trough in the lower and the upper layers, respectively, became steeper at Tateno than at Shionomisaki (see Figs. $4 \mathrm{a}$ and b).

\subsection{Wind field}

Figs. $8 \mathrm{a}$ and $\mathrm{b}$ are the horizontal distributions of relative air current and equivalent potential temperature at the $800-$ and $600-\mathrm{mb}$ levels, respectively. Horizontal distribution was constructed by means of the time-to-space conversion of

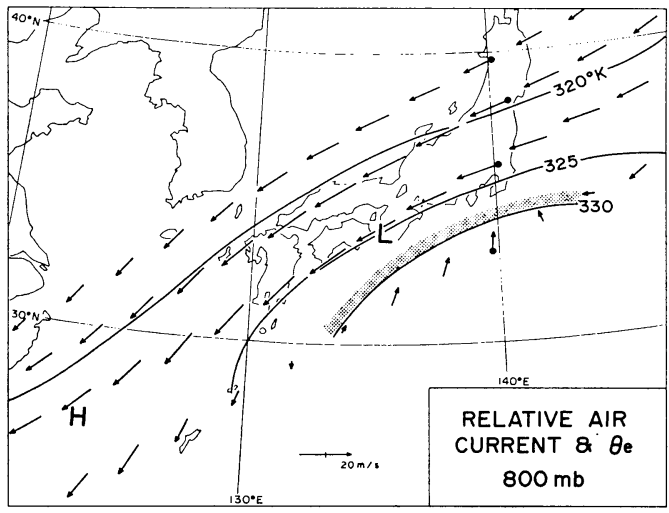

Fig. 8a Relative air current (arrows) and equivalent potential temperature (solid lines in ${ }^{\circ} \mathrm{K}$ ) at $800 \mathrm{mb}$. 


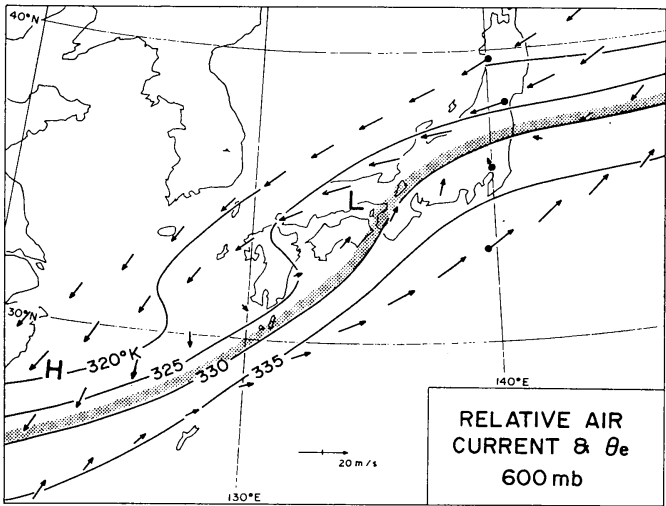

Fig. $8 \mathrm{~b}$ The same as Fig. $8 \mathrm{a}$, except at $600 \mathrm{mb}$.

time changes of each quantity at Hachijojima, Tateno, Sendai and Akita, which were evaluated by adding an analyzed variation with a period of two days to a mean value from 15 JST on the 18th to 09 JST on the 22nd, June, 1969.

It is seen that a surface of $\theta_{e}=330^{\circ} \mathrm{K}$ corresponds with a wind shear zone in the Baiu front, which is a boundary between relative westerly winds on the south side and easterly winds on the north. The surface of $\theta_{e}=330^{\circ} \mathrm{K}$ and the wind shear zone goes up north in the low pressure and down south in the high pressure, indicating the undulation of the Baiu front. The transverse wind component is northward in front of the low and southward in the rear of it. Comparison between Figs. 6 and 8 shows a close relation between the wind field and temperature anomaly distribution. In the southern part of the disturbance positive and negative temperature anomalies are brought by winds with northward and southward transverse component, respectively, and the cold air in the lower layer of the northern part by stronger northeasterly wind. However, a warm core at $600 \mathrm{mb}$ in the low does not seem to be ascribed to adiabatic process of advection. Relative air current there is weak with small wind component across isopleths of equivalent potential temperature, indicating no existence of strong downward motion. Furthermore, a horizontal divergence of sensible heat there is inferred from Figs. $6 \mathrm{~b}$ and $8 \mathrm{~b}$. Therefore, warming there seems to be resulted from diabatic process of latent heat release.

Vertical profiles of divergence, vertical velocity and vertical component of relative vorticity are represented in Figs. 9, 10 and 11, respectively. These quantities are computed from observed winds at four stations, Tateno, Wajima, Shionomisaki and Hachijojima, and therefore they are area-mean values over the area encircled by four stations with a lateral width comparable to that of the disturbance. The variation components with a period of two days are extracted by the procedure previously described. Vertical velocity is evaluated by means of the kinematical method.

In the lower layer below the $800-\mathrm{mb}$ level, horizontal velocity divergence occurs in the high pressure region and convergence in the low pressure region (Fig. 9). In the upper layer between 650 and $400 \mathrm{mb}$, divergence occurs in the low pressure region and convergence in the high pressure region. Its absolute value has maxima of $2 \times 10^{-5} \mathrm{sec}^{-1}$ at $900 \mathrm{mb}$ and of $1.5 \times 10^{-5} \mathrm{sec}^{-1}$ at $600 \mathrm{mb}$. As is inferred from the distribution of divergence and Fig. 8, vertical motion is upward in the trough and downward in the ridge with its maximum speed of about $3.5 \times 10^{-3} \mathrm{mb} /$

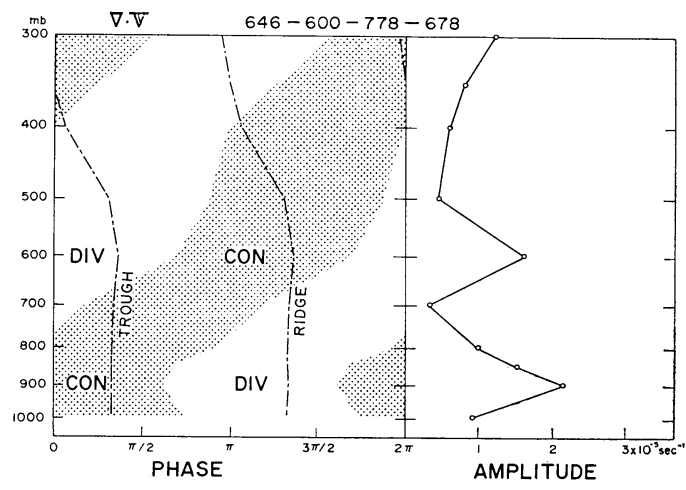

Fig. 9 Vertical profile of analyzed amplitude and phase of area-mean divergence over the area Tateno-Wajima-Shionomisaki-Hachijojima.

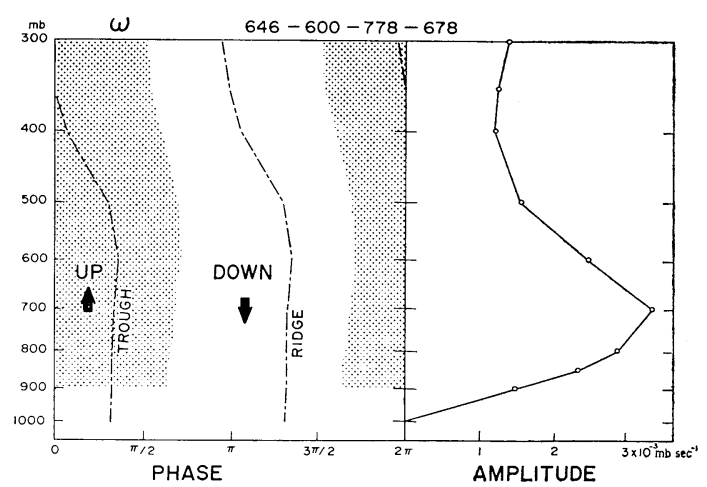

Fig. 10 Vertical profile of analyzed amplitude and phase of area-mean vertical $p$ velocity over the area Tateno-WajimaShionomisaki-Hachijojima. 
sec at $700 \mathrm{mb}$ (Fig. 10). The phase relation between vertical motion and pressure fields is different from that in an ordinary baroclinic wave by about $\pi / 2$. Taking account of lessening the accuracy in estimated vertical velocity with altitude, it may be concluded from Fig. 10 that vertical circulation accompanied by the disturbance extends up to the $400-\mathrm{mb}$ level over the region under consideration.

Figs. 4 and 10 give some information about the kinetic energy flow in the northern part of the disturbance. The kinetic energy is converted from the potential energy in the upper layer where the warm air rises and the cold air falls. In the lower layer, on the other hand, the kinetic energy sink occurs through the descending warm and the rising cold air. This is also expected from Figs. 6 and 8. Distributions of relative air current and equivalent potential temperature in Fig. $8 \mathrm{~b}$ shows that at $600 \mathrm{mb}$ there is upward motion east and north of the low where the temperature anomaly is positive and downward motion around the high where the anomaly is negative. At $800 \mathrm{mb}$ vertical motion is expected to be downward northeast of the high where the temperature anomaly is positive, but it is not clear around the low. Positive correlation between height and vertical $p$-velocity anomalies indicates the downward energy flow from the source in the upper layer to the sink in the lower layer through the work done by the pressure force. The above inferrence about the kinetic energy flow may not hold for the whole disturbance. In fact, Figs. 6a and $8 \mathrm{a}$ indicate that at $800 \mathrm{mb}$ there occurs the conversion from the potential to the kinetic energy south of the low.

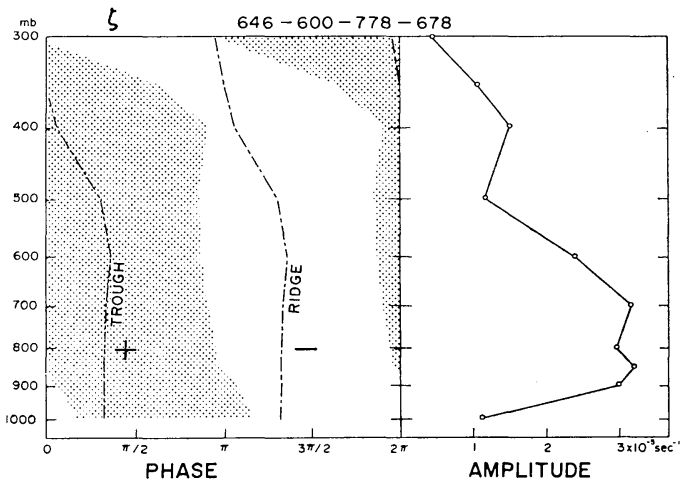

Fig. 11 Vertical profile of analyzed amplitude and phase of area-mean vertical component of relative vorticity over the area Tateno-Wajima-ShionomisakiHachijojima.
Vertical component of relative vorticity is cyclonic in the low pressure region and anticyclonic in the high pressure region, being concentrated in the low layer (Fig. 11). As expected from theoretical discussion (Gambo, 1970a), vorticity has the magnitude of the same order as divergence. Estimated maximum magnitude of the former is about $3 \times 10^{-5} \mathrm{sec}^{-1}$ and that of the latter about $2 \times 10^{-5} \mathrm{sec}^{-1}$.

\section{Disturbance with a period of about one day}

Toward July 10, 1968, intermediate-scale disturbances were predominant on the Baiu front along the southern coast of the Japan Islands. Fig. 12 is the time section of surface pressure anomaly along a line connecting two points, $30^{\circ} \mathrm{N}, 120^{\circ} \mathrm{E}$ and $34^{\circ} \mathrm{N}, 140^{\circ} \mathrm{E}$, from $09 \mathrm{JST}$, July 8 to 09 JST, July 12 . Here the pressure anomaly is a deviation from a running mean of seven 3-hourly observed values. It is seen from this figure that several disturbances move eastwards one after another with a period of one day

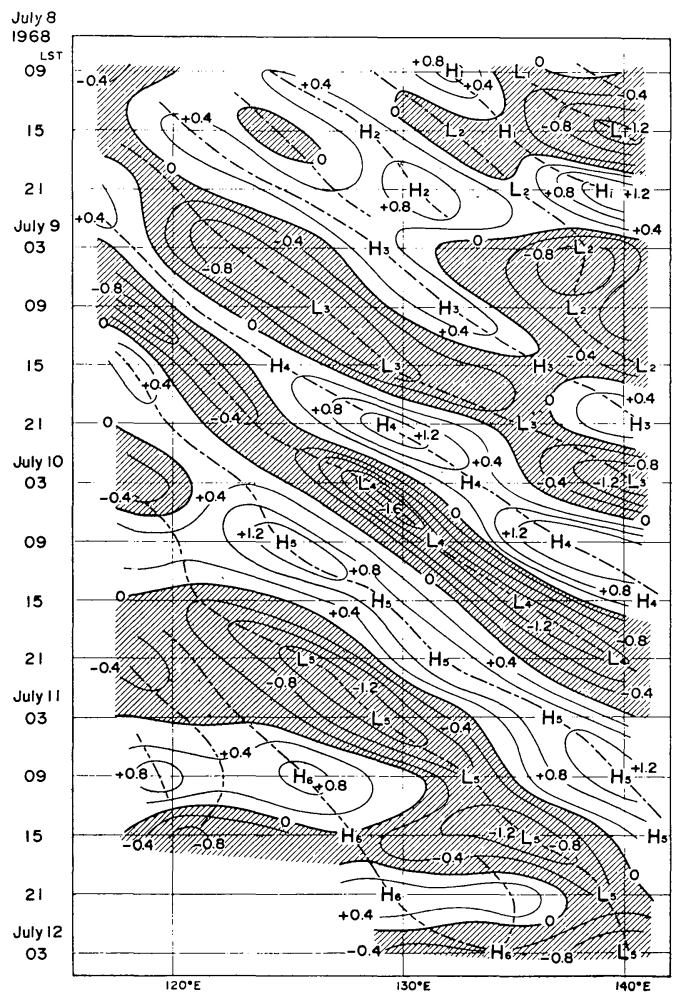

Fig. 12 Time section of surface pressure anomaly along a line connecting two points, $30^{\circ} \mathrm{N}, \quad 120^{\circ} \mathrm{E}$ and $34^{\circ} \mathrm{N}$, $140^{\circ} \mathrm{E}$, from $09 \mathrm{JST}$, July 8 to 09 JST, July 12, 1968. 
and a wavelength of about $1,000 \mathrm{~km}$. MYT pointed out that these gradually developing disturbances have thermal structure different from that of an ordinary baroclinic wave. But they did not describe three-dimensional structure of the disturbance in detail. In the present section, an attempt will be made to reveal some features of three-dimensional structure with composite technique.

\subsection{Data and procedure of analysis}

Data were taken from the first Experiment of the Severe Rainstorms Research Project by the Japan Meteorological Agency made from July 8 to 12,1968 . During this period rawindsonde data at 6-hour intervals were available at all aerological stations of the Japan Meteorological Agency, including two special stations for the project, Fukue (47 843) and Ship Ryofumaru $\left(31.5^{\circ} \mathrm{N}, 128.0^{\circ} \mathrm{E}\right)$ (see Fig. 13 ).

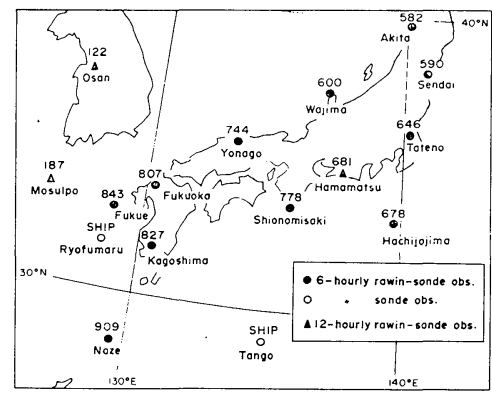

Fig. 13 Location of aerological stations.

Perturbations of various quantities associated with the intermediate-scale disturbance were estimated as a deviation from a running mean of five observed values at 6-hour intervals in order to pick up variations with a period of about one day. As a supplement 12-hourly data at a few stations were added, for which deviations are ones from a running mean over two days. Deviations thus determined contain a large-scale variation with a period of about one day such as a solar diurnal variation. For example, surface pressure anomalies associated with weak disturbances had a smaller amplitude than that of a diurnal variation. As a result, the time section of Fig. 12 tends to show a lateral pattern of alternate stripes of positive and negative anomalies before 03 JST, July 9 and after 15 JST, July 11. Such diurnal variation might distort composite maps of the present case. Accordingly, large-scale variation with a period of about one day were eliminated by taking furthermore a deviation from a space mean over about one wavelength, i.e., a mean value over 11 stations, $47-582,-590,-600,-646,-678,-778,-807,-827$, -909 and Ship Tango, since separation of two variations with nearly the same period by means of an appropriate weighted mean of time-series data only makes short the period of time for which deviations can be computed.

As seen in Fig. 12, six highs and five lows passed along the Japan Islands during the fourday period. Of the five lows, the more pronounced three were accompanied by heavy rainfall (MYT). Composite maps were constructed from aerological soundings around selected 24 highs and 21 lows situated between $125^{\circ} \mathrm{E}$ and $142^{\circ} \mathrm{E}$ on 16 maps at 6-hour intervals. Position of each sounding relative to a moving disturbance was determined in a coordinate system with its origin at the center of the disturbance at surface and its reference azimuth on a meridian passing through the center. The center of a disturbance was fixed from the maps of surface pressure anomaly. Fig. 14 shows composite dis-

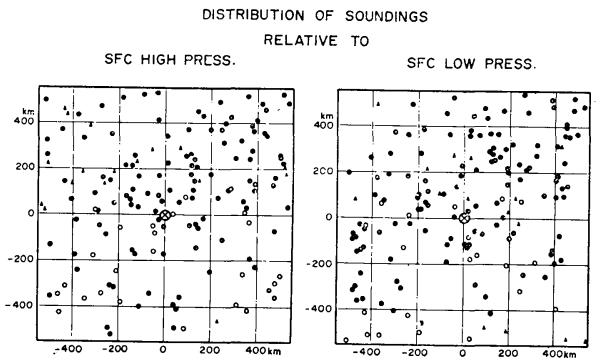

Fig. 14 Distribution of soundings around surface low and high pressures.

tributions of soundings taken for four days around selected highs and lows. Mean densities of soundings around the low and the high are 6.0 and 5.5 per an area of $200 \times 200 \mathrm{~km}$, respectively. Based on anomaly values of soundings at the relative locations, composite maps were constructed for the low and the high separately, and then they were combined into one map for a wavelength.

\subsection{Results}

In Figs. $15 \mathrm{a}$ and $\mathrm{b}$ are shown the composite patterns of height and temperature anomaly at the $800-$ and $600-\mathrm{mb}$ levels. At $800-\mathrm{mb}$ the center of the high coincides well with that at surface, while the center of the low is found at about $150 \mathrm{~km}$ south of that at surface. There is similar discrepancy between the positions of the center of the low at the surface and at the $1,000-\mathrm{mb}$ 


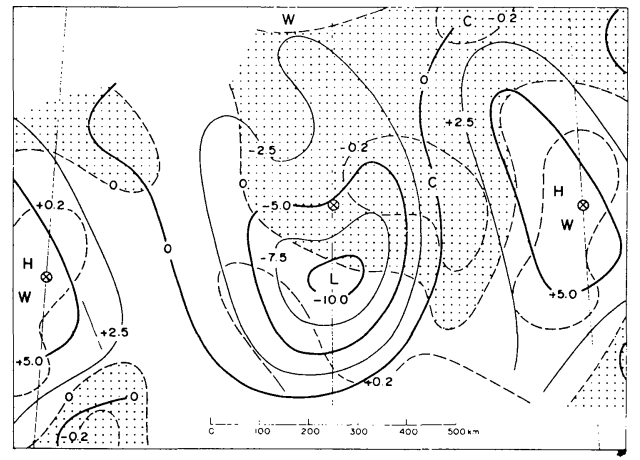

Fig. 15a Composite map of height and temperature anomalies at $800 \mathrm{mb}$, drawn by solid lines labelled in $\mathrm{gpm}$ and by dashed lines labelled in ${ }^{\circ} \mathrm{C}$, respectively. Stippled is area of negative temperature anomaly.

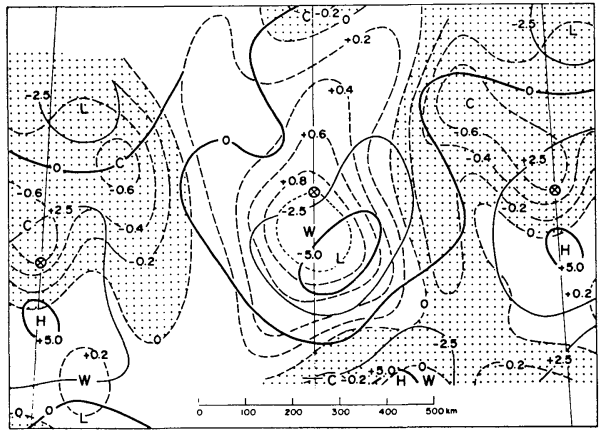

Fig. 15b The same as Fig. 15a, except at $600 \mathrm{mb}$.

level, too. This fact suggests that discrepancy in the position of the lows is due to a bias in composite maps, which was caused by sparse soundings around $300 \mathrm{~km}$ south-southwest of the surface low. Near the center of the analyzed low the composite pattern depends chiefly on the soundings near the center of the surface low. However, southward displacement of analyzed pattern in the low pressure region is tolerable because such bias would appear on resulted composite maps at all other levels and discrepancy is small in the east-to-west direction.

Figs. 15a and $\mathrm{b}$ depict well a thermal field of the disturbance. As pointed out by MYT, in the lower layer it is cold in the low pressure region and warm in the high pressure region, and in the upper layer it is warm in the low and cold in the high. Furthermore, it may be said from comparison between Figs. 6 and 15 that the thermal field shown in Figs. 15a and b represents similar features to those of the disturbance with a wave- length of about $2,500 \mathrm{~km}$. Namely, at $800 \mathrm{mb}$ it is cold in front of the low and warm in the rear of it on the north side, and it seems to be warm in the low and cold in the high on the south side, though not so clear as on the north side. The trough and ridge lines orient NW-to$\mathrm{SE}$ in the northern part and SW-to-NE in the southern part.

The vertical-longitudinal cross section of height and temperature anomalies just north of the analyzed center at $1,000 \mathrm{mb}$ is shown in Fig. 16.

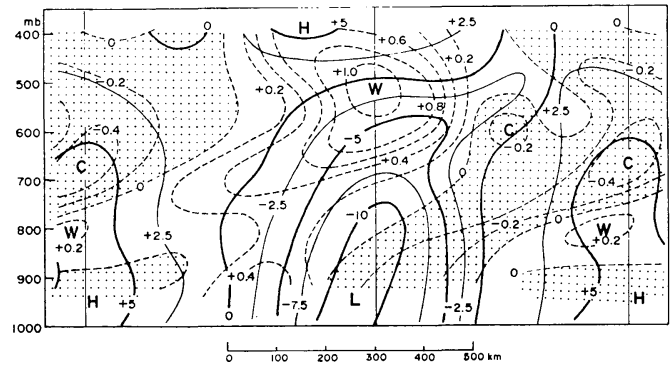

Fig. 16 Vertical-longitudinal cross section. Solid lines denote height anomaly in gpm, and dashed lines temperature anomaly in ${ }^{\circ} \mathrm{C}$. Area of negative temperature anomaly is stippled.

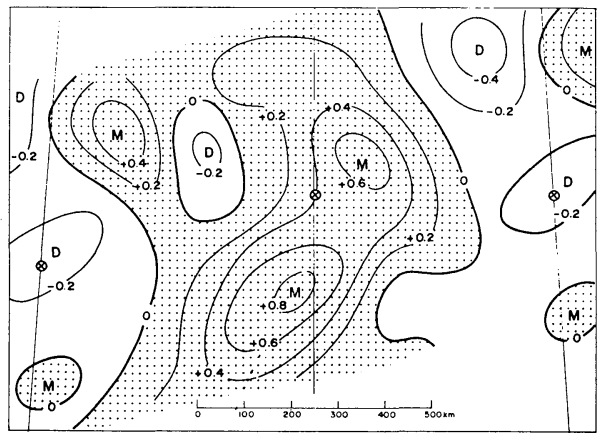

Fig. 17 Composite distribution of mixing ratio anomaly in $\mathrm{gr} / \mathrm{kg}$ at $600 \mathrm{mb}$. Area of positive anomaly is stippled.

The vertical structure is also similar to that in the northern part of the disturbance analyzed in the previous section (see Figs. $4 \mathrm{a}$ and $\mathrm{b}$ ). The axis of the trough has a vertically eastward tilt more markedly. The height anomaly decreases in magnitude with increasing altitude to a minimum at the $500-\mathrm{mb}$ level. The phase in temperature anomaly shifts eastward with increasing altitude between the lower layer, where it is cold in the low pressure, and the upper layer where it 
is warm in the low pressure region.

Fig. 17 is the composite distribution of mixing ratio anomaly at $600-\mathrm{mb}$. Moist area spreads over the low pressure and extends from there southwards, corresponding to a radar echo band revealed by Matsumoto and Tsuneoka (1970). Vertical motion indicated by the moisture anomaly has the phase relation to the height anomaly as that in the disturbance previously treated. A warm core over the low is considered to be caused by non-adiabatic heating in the area of upward motion that is expected from observed heavy rainfall there. Since the moist band extending southwestward is narrower actually, as indicated by the echo pattern, the corresponding upward motion is not expressed by Fig. 8 based on the harmonic analyses.

\section{Some features of large-scale situation}

In this section we shall examine the characteristic features in the mean large-scale fields averaged over the period during which the disturbances with a period of two days were predominant in June, 1969. For the period from July 8 to 12,1968 , similar features can be seen in the paper by MYT.

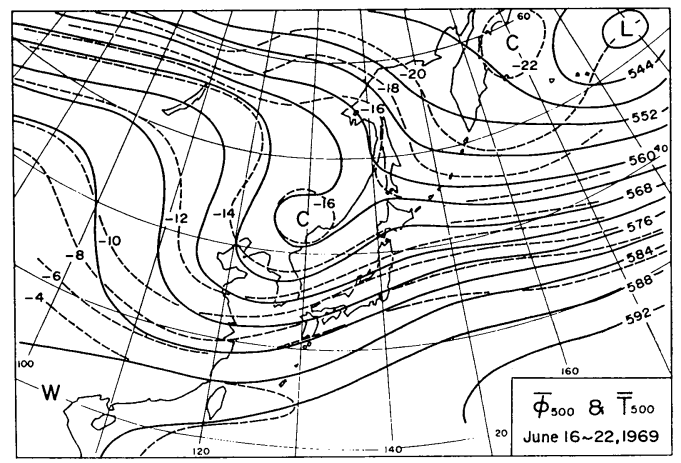

Fig. 18 Distribution of mean height and temperature on the $500-\mathrm{mb}$ surface over the period from June 16 to 22, 1969. Contours are drawn by solid lines labelled in $10 \mathrm{gpm}$, and isotherms by dashed lines in ${ }^{\circ} \mathrm{C}$.

Fig. 18 shows the distribution of mean height and temperature on the $500-\mathrm{mb}$ surface over the period from June 16 to 22,1969 . On the mean $500 \mathrm{mb}$ map there exists a cold trough extending southwestward from the Sea of Okhotsk through the Marine Province to the Yellow Sea. South of the cold trough a zone of concentrated temperature gradient runs west-southwest to east- northeast along the Japan Islands, which indicates the existence of a strong jet stream in the upper troposphere. Another zone of concentrated temperature gradient lies along the latitudinal circle of about $60^{\circ} \mathrm{N}$ in Siberia. Such double jet-stream flow pattern is a typical situation in the Baiu season (Murakami, 1951).

From their statistical study, Nitta and Yamamoto (1973) points out a close relationship between the monthly mean flow pattern on the $500-\mathrm{mb}$ map and the monthly cyclogenesis on intermediate scale. When the mean $500-\mathrm{mb}$ flow shows a zonal or flat pattern, cyclogenesis of intermediate-scale increases in number. When the upper trough is situated west of the Japan Islands, the generation of intermediate-scale disturbances decreases and that of ordinary baroclinic disturbances becomes active. In Fig. 18 the flow pattern in the vicinity of the Japan Islands is obviously flat, but the trough is situated west of Japan. A synoptic condition that in the mean field over one-week period a trough is located west of Japan seems to be not unfavorable for the development of an individual intermediate-scale disturbance, though such condition in the monthly mean field may diminish the total number in monthly cyclogenesis on intermediate scale.

In order to see the feature of atmospheric stratification in the mean fields, the vertical cross

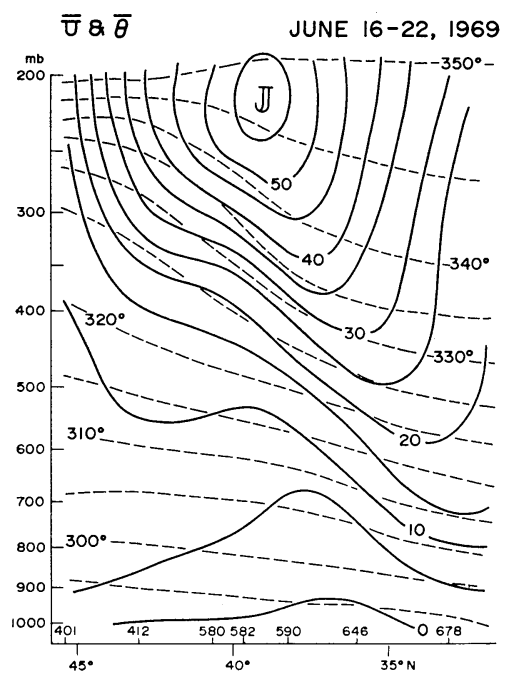

Fig. 19 Vertical-meridional cross section of mean zonal wind component (solid lines in $\mathrm{m} / \mathrm{sec}$ ) and potential temperature (dashed lines in ${ }^{\circ} \mathrm{K}$ ) along $140^{\circ} \mathrm{E}$ over the period from June 16 to $22,1969$. 
sections of mean zonal wind component and potential temperature were drawn along $140^{\circ} \mathrm{E}$ for the periods from June 16 to 22 and from June 25 to 30 . It can be seen from the two cross sections that there exists a remarkable difference between the mean stratifications for the two periods. The mean wind and temperature fields (Fig. 19) for the period from June 16 to 22, during which intermediate-scale disturbances occurred, were quite similar to the cross section of active Baiu frontal zone: a strong upper jet stream with a maximum speed exceeding $55 \mathrm{~m} / \mathrm{sec}$ and strong vertical and horizontal wind shear and the weak horizontal temperature gradient in the lower troposphere (c.f., MYT; Matsumoto, Ninomiya and Yoshizumi, 1971). On the other hand, for the period from June 25 to 30 , during which synoptic-scale disturbances were predominant, the upper jet stream in the mean field is weak with a maximum wind less than $40 \mathrm{~m} / \mathrm{sec}$ and there was no zone of concentrated temperature gradient throughout the troposphere.

Fig. 20 is the distribution of Richardson $(R i)$ number in the meridional cross section along $140^{\circ} \mathrm{E}$ for the period from June 16 to 22,1969 . $R i$ numbers were calculated for layers with $100 \mathrm{mb}$ thickness by the use of mean observed winds and temperatures. A region with low $R i$

$\mathrm{Ri}$

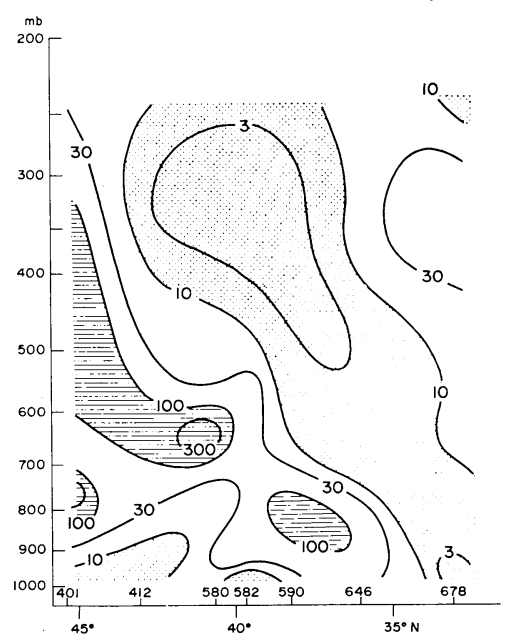

Fig. 20 Vertical-meridional cross section of Richardson number along $140^{\circ} \mathrm{E}$, which was calculated from mean observed wind and potential temperature over the period from June 16 to 22, 1969. Areas of Richardson number less than 10 and larger than 30 are stippled and horizontally hatched, respectively. number of unity, necessary for the development of intermediate-scale baroclinic waves, can be found out along the Baiu frontal zone. In contrast with this distribution, for the period from June 25 to 30 , calculated $R i$ number is less than 10 only in the surface boundary layer and just below the jet-stream core. In the mid-troposphere calculated values range from 30 to 300 , i.e., about the normal value (c.f., Magata and Nishida, 1971).

It is, however, evident from comparison between Figs. 5 and 20 that the disturbance did not develop within the region with low $R i$ number, and its northern part lies in a region with $R i$ number larger than 30. Similar situation seems to hold for the disturbance with a wavelength of about $1,000 \mathrm{~km}$ in July, 1968, as seen from Figs. 6 and 13 in MYT. This means that the horizontal non-uniformity in the large-scale wind field and vertical stratification must be taken account of for a full understanding of the disturbances. Horizontal wind shear may be important for the development of the disturbances, too. Analyzed wind variations at Hachijojima at the 800-mb level (Fig. 8a) and at Tateno at the 600$\mathrm{mb}$ level (Fig. 8b) indicate that in the Baiu frontal zone the disturbance carries the horizontal momentum northwards, i.e., that the disturbance obtains its kinetic energy from the large-scale motion field, too. In addition to convective heating (Tokioka, 1973), the horizontal wind shear may be an important factor in determination of the wavelength of the disturbance. In the case of July, 1968, the mean amount of the rainfall was larger and the mean Baiu frontal zone was narrower in width than in the case of June, 1969.

The low $R i$ number region is also found near $300-\mathrm{mb}$. It is interesting that in this region analyzed amplitudes of height variation increases again (Figs. 4b and c). This may indicate that the disturbance extends up to the low $R i$ number region in the upper troposphere or that another disturbance exists. It is, however, necessary to make a careful analysis further since the analyzed amplitudes may be affected by longer-period and diurnal variations with large amplitude in the upper troposphere.

\section{Concluding remarks}

In this study detailed analyses were made for three-dimensional structure of two developing intermediate-scale disturbances on the Baiu front. One has a wavelength of about $2,500 \mathrm{~km}$ and the other about $1,000 \mathrm{~km}$. These disturbances have 
a similar structure. The characteristics of their structure are as follows:

(1) The disturbance has a shallow vertical extension below the 400-mb level.

(2) The vertical structure is different between north of and in the mean Baiu frontal zone. North of the front, it is cold in the low pressure region and warm in the high pressure region, and on the longitudinal cross section the axes of the trough and the ridge have a slightly forward or eastward tilt. In the frontal zone it is warm in the trough and cold in the ridge, and the axes of the trough and the ridge tilt backward or westward vertically. This means that a single longitudinal cross section is not enough to reveal thoroughly characteristics of intermediate-scale disturbances.

(3) On the horizontal map, the trough and the ridge lines run NW-to-SE in the northern part and SW-to-NE in the southern part.

(4) The disturbance is of a warm-core type. A warm core near 600 -mb over the low is considered to be resulted from the non-adiabatic heating due to the latent heat release and intensified with the development of the disturbance.

(5) Horizontal velocity divergence and vertical component of relative vorticity are of the same order in magnitude.

(6) The disturbance developed in a narrow zone of strong gradient of $R i$ number in the mean field averaged over the several-day period. This fact, together with (2), (3) and (4), suggests that a theoretical discussion with a three-dimensional model is necessary for full understanding of the disturbance.

\section{Acknowledgements}

The author would like to express his hearty thank to Dr. K. Ninomiya for his encouragement throughout this study and to Dr. N. Saito for careful reading of the manuscript. Thanks are also due to Mrs. K. Sakurai and Miss H. Imai for invaluable assistance and drafting.

\section{References}

Eliassen, A., 1966: Motions of intermediate scale; fronts and cyclone. In Advances in Earth Science, MIT Press, 11-138.

Gambo, K., 1970a: The characteristic feature of medium-scale disturbances in the atmosphere (I). J. Meteor. Soc. Japan, 48, 173-184.

- 1970b: The characteristic feature of medium-scale disturbances in the atmosphere (II). J. Meteor. Soc. Japan, 48, 315-330.

Kasahara, A., and D. B. Rao, 1972: Instability of frontal motions in the atmosphere. J. Atmos. Sci., 29, 1090-1108.

Magata, M., and K. Nishida, 1971: Statistical properties of the atmosphere. Tenki, 18, 399-406. (in Japanese.)

Manabe, S., J. Smagorinsky, J. L. Holloway, Jr., and H. M. Stone, 1970: Simulated climatology of a general circulation model with a hydrologic cycle. III. Effects of increased horizontal computational resolution. Mon. Wea. Rev., 98, 175-212.

Matsumoto, S., K. Ninomiya and S. Yoshizumi, 1971: Characteristic features of "Baiu" front associated with heavy rainfall. J. Meteor. Soc. Japan, 49, 267-281.

, and Y. Tsuneoka, 1970: Time lapse composite echo pattern of wave disturbances embedded on the Baiu front. J. Meteor. Soc. Japan, 48, 198-203.

$\longrightarrow$, S. Yoshizumi and M. Takeuchi, 1970: On the structure of the "Baiu front" and the associated intermediate-scale disturbances in the lower atmosphere. J. Meteor. Soc. Japan, 48, $479-491$.

Murakami, T., 1951: On the study of the change of the upper westerlies in the last stage of Baiu season (rainy season in Japan). J. Meteor. Soc. Japan, 29, 162-175.

Ninomiya, K., and T. Akiyama, 1971: The development of the medium-scale disturbance in the Baiu front. J. Meteor. Soc. Japan, 49 (Special Issue), $663-677$.

Nitta, Ta, and Y. Ogura, 1972: Numerical simulation of the development of the intermediate-scale cyclone in the moist model atmosphere. J. Atmos. Sci., 29, 1011-1024.

the formation of intermediate-scale disturbances near Japan, the western Pacific and southern Asia. Pap. Meteor. Geophys., 24, 289-309.

, 1974: On the observational characteristics of the intermediate-scale disturbances generated near Japan and the vicinity. J. Meteor. Soc. Japan, 52, 11-31.

Nitta, Ts., M. Nanbu and M. Yoshizaki, 1973: Wave disturbances over the China Continent and the Eastern China Sea in February 1968. J. Meteor. Soc. Japan, 51, 11-28.

Orlanski, I., 1968: Instability of frontal waves. J. Atmos. Sci., 25, 178-200.

Saito, N., 1966: A preliminary study of the summer monsoon of southern and eastern Asia. J. Meteor. Soc. Japan, 44, 44-59.

Sawyer, J.S., 1967: Weather forecasting and its future. Part I. Weather, 22, 350-360.

Stone, P. H., 1966: On the non-geostrophic baroclinic stability. J. Atmos. Sci., 23, 390-400. 
Tokioka, T., 1970: Non-geostrophic and non-hydrostatic stability of a baroclinic fluid. J. Meteor. Soc. Japan, 48, 503-520.

, 1971: Supplement to non-geostrophic and non-hydrostatic stability of a baroclinic fluid and medium-scale disturbances on the fronts. $J$. Meteor. Soc. Japan, 49, 129-132. , 1972: A numerical experiment of mediumscale disturbances: Dry model. J. Meteor. Soc.
Japan, 50, 259-270.

1973: A stability study of medium-scale disturbances with inclusion of convective effects. J. Meteor. Soc. Japan, 51, 1-10.

Yoshizumi, S., 1974: Medium-scale disturbances developed along the Baiu frontal zone. In $R e$ port on the Severe Rainstorms in Japan, Tech. Report Japan Meteor. Agency, No. 86, 67-83. (in Japanese.)

\title{
梅雨前線帯上の中間規模じょう乱の構造
}

\author{
吉 住 禎 夫 \\ 気象研究所
}

梅雨前線帯上を発達しながら東進した，波長約 $2,500 \mathrm{~km}$ および $1,000 \mathrm{~km}$ の中間規模じょう乱の構造を調べた。 前者については, 各観測点での 6 時間間隔の高層資料の調和解析に基づき, また, 後者については, いくつかのじょ う乱を合成することにより,じょう乱の構造を解析した。

解析結果は, 両じょう乱ともに似を構造をもつことを示し, 次のよらな特徵を挙げることができる。

(1) $400 \mathrm{mb}$ 面以下の背の低いじょう乱である。

（2）梅雨前線帯の北側では，低圧域で低温，高圧域で高温であり，trough の軸は前方 (東) に傾いている。前線帯 付近では, 低圧域で高温, 高圧域で低温で, trough の軸は後方(西)に傾いている。

（3）水平断面では， trough の走向は，北側で NW-SE，南側で SW-NE である。

（4）低圧域の上空 $600 \mathrm{mb}$ を中心に warm core が存在し, ごょう乱の発達に伴って強まる。 warm core の形 成には，水蒸気潜熱の解放が重要であると考兄られる。

(5) じょら乱に伴う水平速度発散と相対渦度の鉛直成分の大きさは，同じオーダーである。

（6）数日間の平均場に执いて，1のオーダーの低 Richardson 数域の近くで，じょう乱は発達している。しかし 低 Richardson 数域内でなく，すぐ北側の傾度の大きい所に発達域が見出される。 